\title{
Coronary crossing
}

\author{
J. J. D. de Jong $\cdot$ H. Tent
}

Accepted: 9 November 2020 / Published online: 30 November 2020

(C) The Author(s) 2020

A 46-year-old male was sent to our outpatient clinic because of an abnormal exercise stress test, which was performed for sports screening. He was asymptomatic. Coronary computed tomography angiography showed no atherosclerotic coronary artery disease. However, a crossing was seen of a diagonal branch with the left anterior descending artery (Fig. 1). There was no compression of either vessel. Therefore, the crossing was considered to be benign and the exercise test to be false-positive.

The epicardial crossing of coronary arteries has been published in only a dozen of cases worldwide and is still considered to be impossible by many. Whether coronary crossing is a rarity or it is often overlooked, is debatable. Back in 1985, Muyldermans et al. reported a case series from their own catheterisation laboratory [1]. The crossing of coronary arteries was considered pathological in none of the published cases, which may also explain the low incidence of reporting.

Conflict of interest J.J.D. de Jong and H. Tent declare that they have no competing interests.

Open Access This article is licensed under a Creative Commons Attribution 4.0 International License, which permits use, sharing, adaptation, distribution and reproduction in any medium or format, as long as you give appropriate credit to the original author(s) and the source, provide a link to the Creative Commons licence, and indicate if changes were made. The images or other third party material in this article are included in the article's Creative Commons licence, unless indicated otherwise in a credit line to the material. If material

J. J. D. de Jong ( $\triangle)$

Medisch Spectrum Twente, Thorax Center, Enschede, The Netherlands

jjd.dejong@mst.nl

J. J. D. de Jong $\cdot$ H. Tent

Martini Hospital, Groningen, The Netherlands

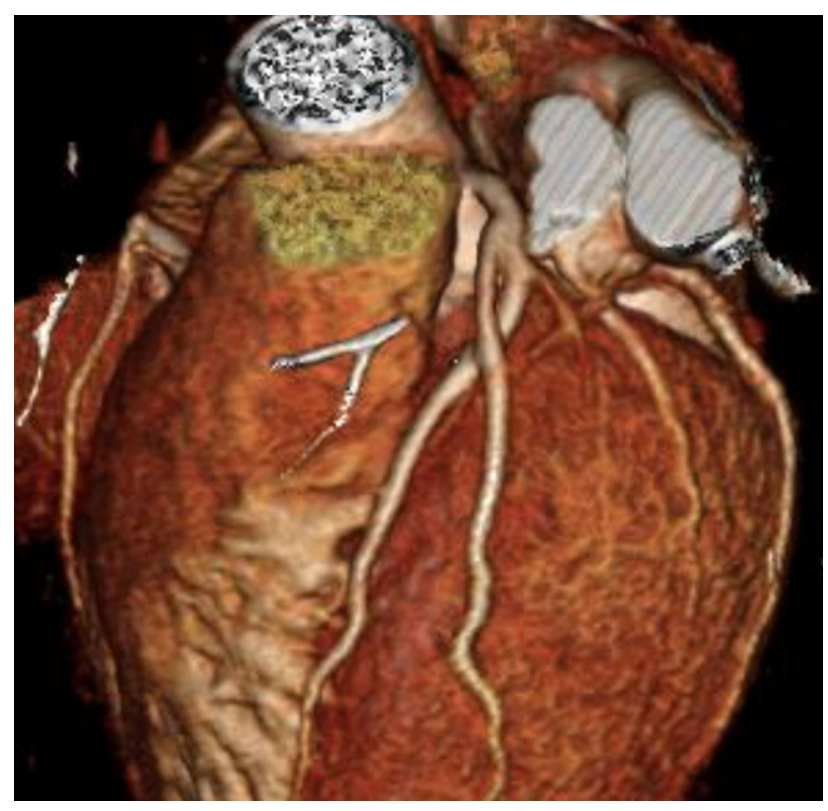

Fig. 1 Crossing between a diagonal branch and the left anterior descending artery. The diagonal branch is seen branching off from the left main coronary artery, then crossing over the left anterior descending artery to follow its usual course

is not included in the article's Creative Commons licence and your intended use is not permitted by statutory regulation or exceeds the permitted use, you will need to obtain permission directly from the copyright holder. To view a copy of this licence, visit http://creativecommons.org/licenses/by/4.0/.

\section{References}

1. Muyldermans LL, Van den Heuvel PA, Ernst SM. Epicardial crossing of coronary arteries: avariation of coronary arterial anatomy. Int J Cardiol. 1985;7:416-9. 